The object of performing the experiments with several magnets, is to eliminate as far as possible, errors in the determination of weight and length. The mean of the values of $H$, found for the several magnets, is to be taken as the value of $H$ at the place of the magnetometer. We Gave now to apply this value to the measurement of currents.

(To be continued.)

ANDREW GRAY

\section{THE ITALIAN EXPLORATION OF THE MEDITERRANEAN}

I BELIEVE it will interest the numerous readers of NATURE, especially those who have studied the important subject of the deep-sea fauna, or who are geologists, to learn that the further exploration of the Mediterranean this year, on the part of the Italian Government, has not been fruitless, although it has been short. I have just received a letter from Prof. Giglioli, of Florence, the purport of which I will, with his permission, now give :-

It seems that this summer the surveying-vessel, Washington, had to undertake a search (which proved unsuccessful) for some imaginary coral-banks in the shallow sea between Sicily and Africa, besides her usual hydrographical work, and that consequently very little time could be devoted to deep-sea exploration. However, Prof. Giglioli was allowed to accompany the hydrographer, Capt. Magnaghi, with the chance of taking any favourable opportunity that might occur. He thus got three deepsea hauls: the first near Marittimo, in 7I8 metres, or about 389 fathoms; the second, half-way between Sicily and Sardinia (lat. $38^{\circ} 38^{\prime}$ N., long. $10^{\circ} 40^{\prime}$ E.), at a depth of 1583 metres, or about 857 fathoms, when a very rare and peculiar abyssal fish (Paralepis cuvieri), was obtained. That day (August I5) was also appropriated to hydrographical researches, and particularly to the successful trial of Capt. Magnaghi's new water-bottle, as well as to the marvellous work of his new currentometer, a most valuable discovery, by means of which the direction and force of sub-marine currents can be accurately determined at any depth. A large new trawl was used, and brought up a block of newly-formed limestone, which had been hardened with recent shells of Pteropods embedded in its mass. The third and last deep-sea dredging was made on September I, between Tavolara in Sardinia, and Montecristo, in 904 metres, or about 490 fathoms, with indifferent results. He will send me the shells for examination. The Italian Ministry have promised him that a whole month next year will be allowed for deepsea exploration. J. CWYN JEFFREYS

\section{WIRE GUNS ${ }^{1}$}

\section{II.}

$I^{\mathrm{T}}$ Thas been necessary to dwell thus at length on the hoop method of construction in order to contrast it with the wire system, which we now proseed to describe.

A wire gun consists first of an internal tube, the function of which is to contain the rifling, and to transmit the internal pressure to the wire which is coiled upon it, and which gives the strength. This tube no doubt has a certain amount of strength of its own, but this is not its real function. The gun may be so designed and constructed that the tube is never in a state of tension. It may therefore be made, and possibly with advantage, of hard cast iron. In the 3 inch breech-loading gun made by the writer in 1860 , the tube was of cast-iron $\frac{1}{2}$ inch thick, and this gun has been severely tested without injury. Hard cast-iron possesses many advantages, and amongst others that of great economy as compared with the steel tubes now generally used; but whatever be the

\footnotetext{
${ }^{I}$ Continued from p. I4
}

material of the tube, its principal function is to contain the rifling and transmit the strain to the wires coiled around it.

Upon the inner tube is wound steel wire, square or rectangular in section. The tube is mounted in a machine similar to a lathe, and the wire is coiled upon one or more cylindrical drums, which are fixed horizontally on axes parallel to the tube and provided with proper apparatus for regulating the feed and tension. The tensions having been first calculated, the coiling begins from the breechend where the end of the wire is made fast. When the muzzle end is reached the wire is coiled back again to the breech, and this process goes on till the whole of the coils are in place. The end of the wire is then made fast, and the gun, so far as strength to resist a bursting strain, which is called circumferential strength, is concerned, is complete.

Before proceeding to show how the longitudinal strength is provided for, it will be well to devote a little time to the substitution of coils of wire for the hoops above described, pointing out as we go along the superiority of the wire system. It has already been shown how important it is in the hoop system that the initial tensions

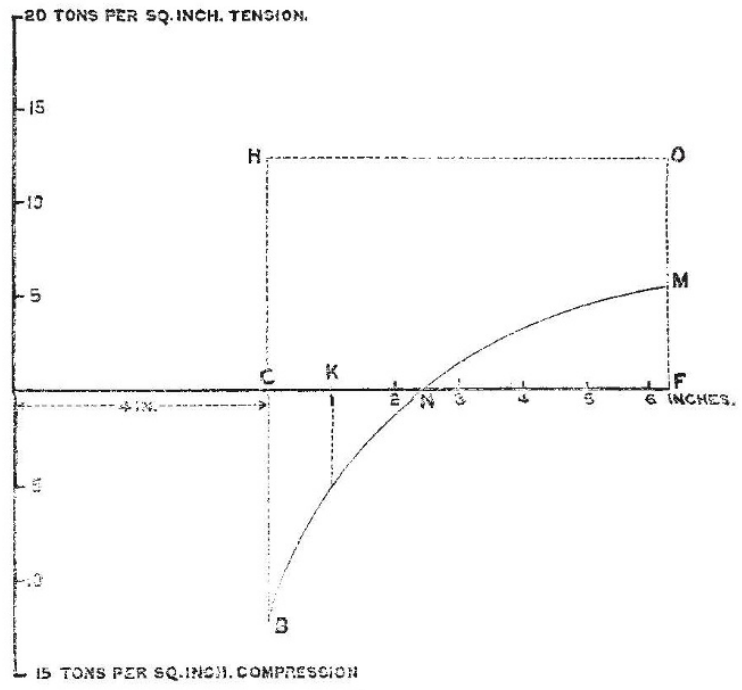

E

of each hoop should be accurately calculated and applied. This is no less necessary with the wire coils, and it would at first appear that this must involve very intricate and tedious calculation. In the case of the gun represented in Diagram c, it was stated that the same strength which was given by 4 coils of steel, making with the tube a total thickness of $22 \frac{3}{4}$ inches, might be obtained by $6 \frac{3}{4}$ inches of wire, but supposing the wire to be ${ }_{1}^{\frac{1}{0}}$ th inch square in section there would be required no less than 67 different coils and tensions, and as it is desirable to use even smaller wire for the first portion of the ccils, there would probably be not less than 80 or 90 coils and the same number of tensions to be calculated. A formula has, however, been found which makes these calculations comparatively simple. In order to make this intelligible we must resort to another diagram, E, which represents the state of strain of the interior of a wire gun, or rather of the wire portion of it, on which alone we depend for circumferential strength. Assuming the wire to be very small, say $\frac{1}{16}$ th of an inch square in section, the strains are represented very nearly by the curved line B N M. The coils between the inner circumference, i.e. the first coil, and the point $N$ are all in compression, the maximum being at $\mathrm{C}$; at $\mathrm{N}$ is the neutral point, when the wire is neither in compression nor tension; and from $\mathrm{N}$ to $\mathrm{F}$ all the coils are in tension, the maximum being at $\mathrm{F}$. 
Now if we consider the case of any one coil, such as that at the position $\mathrm{K}$, we see that when the gun is completed it is under considerable compression, but whilst the construction is proceeding, when the coil at this point is being laid on, it is laid on under tension, which tension is reduced by every successive additional coil until it attains the state of compression shown in the diagram of the finished structure. The question therefore to be solved is this, What is the proper tension for putting on the coil at $\mathrm{K}$, so that when all the other coils are put on, it may be in the required state of compression? This problem must be solved for every individual coil. This having been done, each coil is laid on by automatic machinery with its proper tension, and the final result is that shown in the diagram.

When the full internal pressure of the explosion operates, the result is as follows :-Every coil is brought up to the same tension simultaneously and exerts the same resistance per square inch of section throughout the whole thickness of the gun as denoted by the line $\mathrm{H} \mathrm{O}$.
The ultimate strength therefore of such a gun increases in the simple ratio of the number of coils, a result not attainable by any other mode of construction, and this is the first advantage over the hoop system. The second is, that there is no fear of error through inaccurate workmanship or unequal.shrinkage. The tensions of the wire coils are actually measured by the machine by which they are laid on, instead of being inferred from presumed accuracy of workmanship or uniform shrinking power of the material. In the next place there is no danger from latent defects. The wire is not subject to such defects as thick hoops are, and can moreover be easily tested before it is applied. Then again the process of construction is simple and expeditious, it is the substitution of accurate automatic machinery for very highly skilled labour. Beyond this it is much less costly, for although the wire itself costs a high price per ton as compared with the raw material used in the hoops of the Woolwich guns, yet when the labour and work in the latter is taken into account, it will be found that it largely exceeds that of

Fig. I.
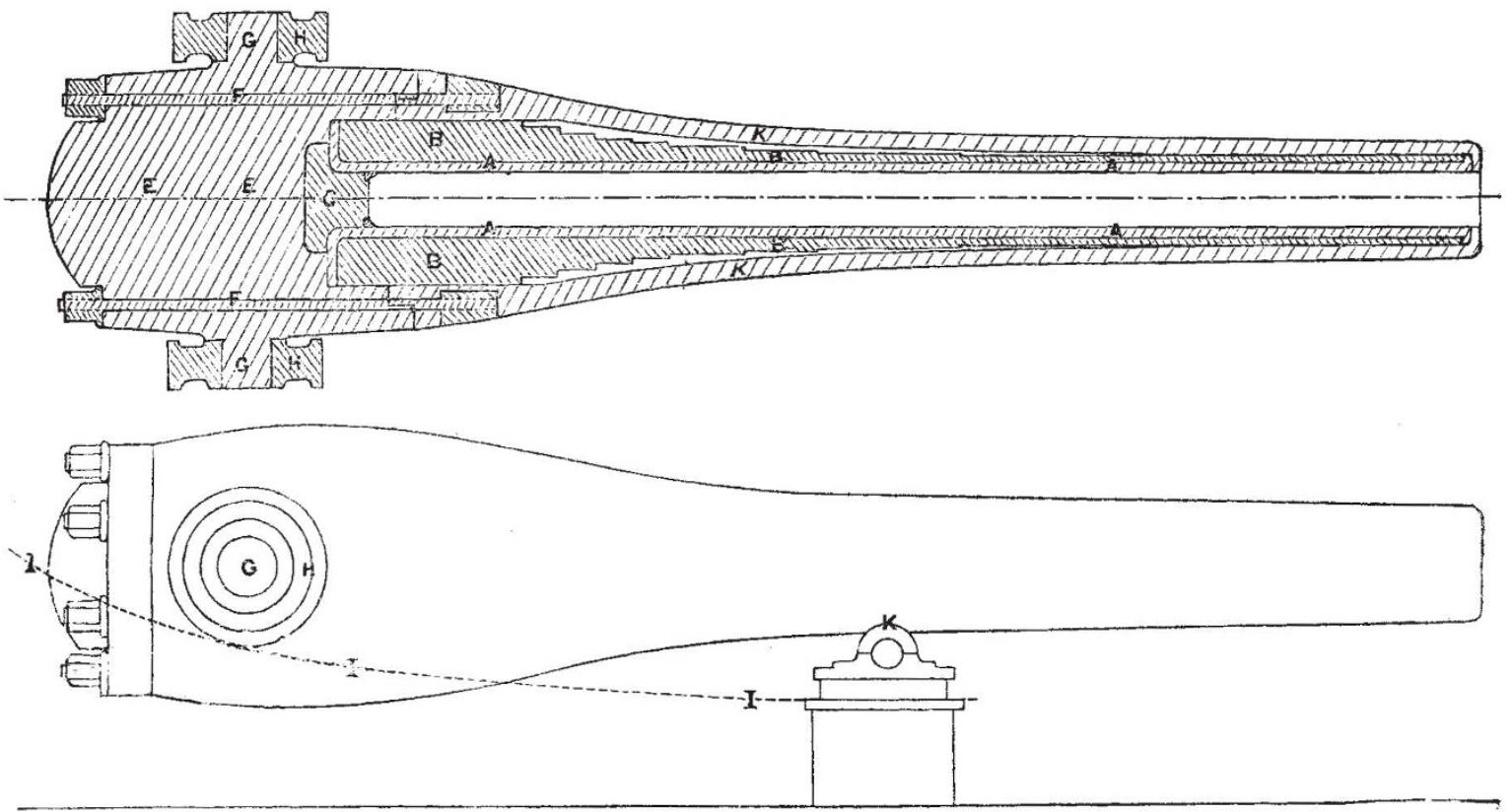

FIG. 2.

the wire gun ton for ton, and as was before pointed out, the wire gun of equal strength can be made very much lighter.

In a paper read before the Institution of Civil Engineers in 1879 the writer estimated the cost of a muzzleloading 20 inch gun weighing 150 tons, constructed on the wire principle, at $£ 5,04 \mathrm{I}$, or $£ 33 \mathrm{I} 6 \mathrm{~s}$. per ton. We believe that the price paid by Government to Sir Wn. Armstrong for the roo-ton guns produced from his firm was $£ 16,000$ cach, or $£ 160$ per ton.

We now proceed to the question of longitudinal strength. In the old guns, as well as the present Woolwich guns, the Armstrong, Whitworth, and Krupp guns, the longitudinal strain between the breech and the trunnions is borne by the chase of the gun itseif, that is to say, that the same material which has to resist the enormous circumferential strain bas at the same time to resist a very intense longitudinal strain. Now it has been generaily maintained that although this is very large in the gross, yet when it is divided by the sectional arm of the chase, it is comparatively small per square inch of section. This is a very great mistake as was pointed out several years ago by the late Sir William Palliser. The fact is, that this strain is no more uniformly divided over the sectional area of the chase than is the circumferential strain between the inner and outer circumferences.

Sir Wm. Palliser devised a method of breech construction which has since been adopted at Woolwich, by means of which the longitudinal strain is much more equally distributed, and since then the accident of a breech blowing out has been comparatively rare, and we believe has never occurred in Sir Wm. Palliser's own guns. It has always been a difficulty with many people to understand how the breech is to be secured in a wire gun. It is obvious that the coils of wire afford no longitudinal strength, and the general idea has been that it was therefore necessary to resist the whole longitudinal strain by the inner tube.

The writer has always maintained that no real diffculty exists, and that the connection between the breech and the trunnions should be by means of material quite independent of and placed outside of the coils of wire. 
It was in this way that his gun made in 1860 was constructed, and we believe the same principle has been adopted by Capt. Schultz in the wire guns built under his directions by the French Government. Thus the circumferential strain is provided for by one portion of material, and the longitudinal strain by another, and it does not admit of a doubt that this is far preferable to subjecting the same material to two strains at right angles to each other at one and the same time.

Another objection has been taken to wire guns, and it is this. It is well known that guns become heated by firing, and it is thought that this heating would disturb

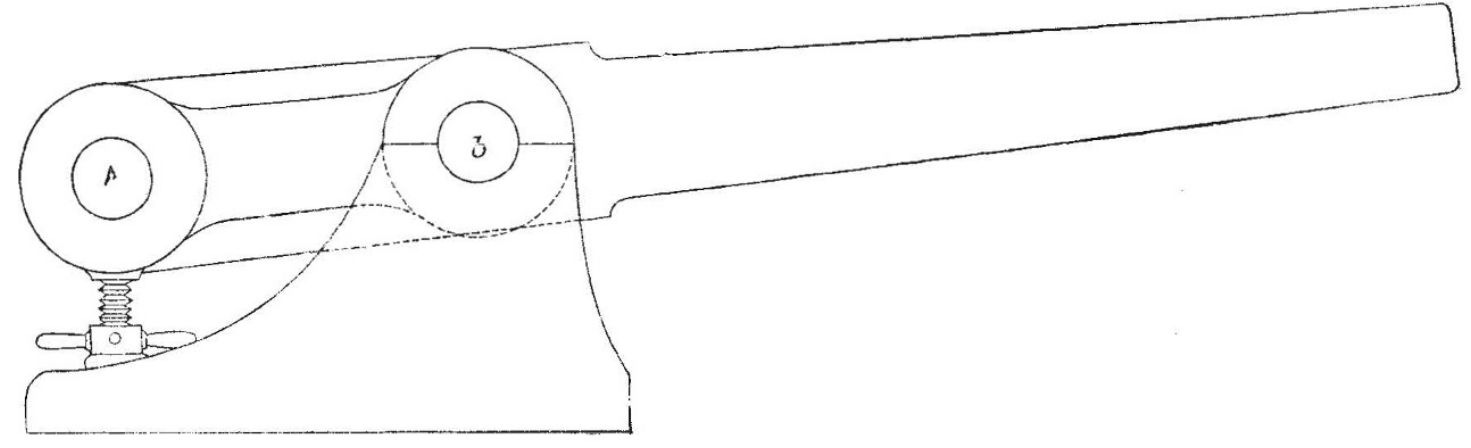

FIG. 3.

the tensions to such an extent as to render all the calculations of strain useless. Now if this be an objection, it applies with far greater force to the system of hoop construction than to that of wire, but as there is much misconception on this point it is desirable to say a few words about it.

In the first place, it is a mistake to supfose that the heating of guns depends chiefly on the heat absorbed by the metal from the powder gases. Though this heat is very intense, its application is for a very small fraction of a second, and it may be shown that in this very short time only a small amount of heat can be absorbed by the surface of the gun exposed to it. It may further be shown, that during the very short time the heat is

F1G. 4.
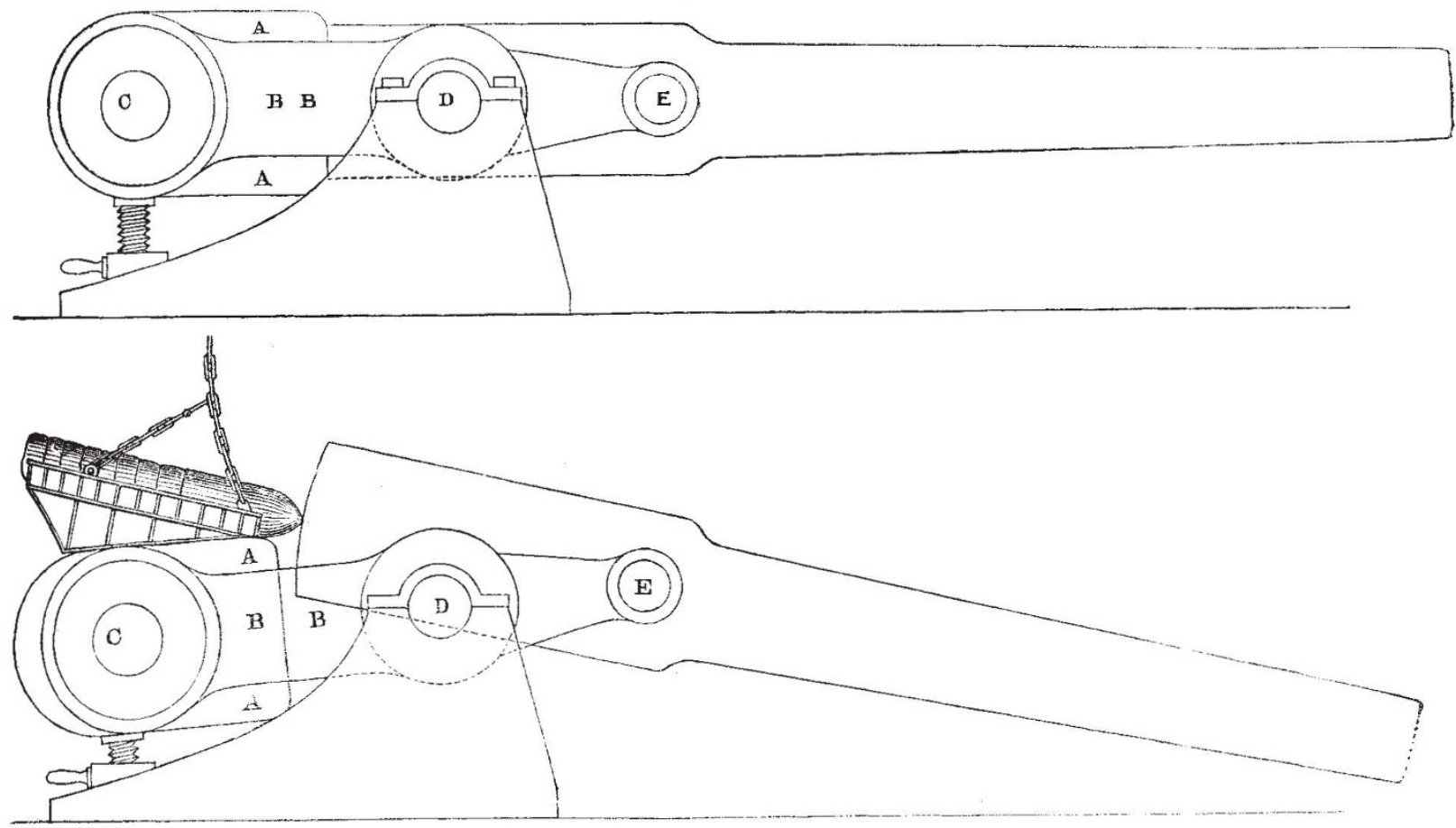

FIG. 5

applied, it can only be transmitted by internal conduction to a very small depth into the metal of the gun. But as guns do heat by firing, how is this to be accounted for ?

The reason seems to be the following. By the explosion of the powder, a considerable amount of mechanical energy is absorbed in expanding the gun against the elastic form of the material. When the projectile leaves the gun, the internal pressure is removed, the mechanical energy is thus given back, but as it does no external work, it appears in the form of heat, which remains in the metal of the gun, until it is dissipated by convection through the surrounding air.

We are quite aware that this explanation does not agree with the views of some physicists of great reputa- 
tion. For instance, in a recent discussion at the Institution of Civil Engineers, Dr. Siemens asserted that not a single unit of heat would be set up in the body of the gun by compressive action, and maintained that the whole heat produced was due to the heated products of combustion of the powder. But an experiment recorded by Hirn in his Treatise on Thermodynamics seems to support the view we have above set forth. He found that if an elastic bar of india-rubber was extended by tension it grew sensibly warmer, if then it was allowed to contract by the gradual decrease of the extending force, it cooled again to its original temperature; but if on the contrary it was let go suddenly, it did not cool, but remained at its higher temperature. In the one case the mechanical energy was given out in work done in the extending force, whilst in the other no external work was done. This is exactly what happens in the gun.

There is moreover another cause which operates in heating the body of a gun. The explosion of powder is an impact. Now in the impact of two elastic bódies one portion of the vis viva is expended in overcoming the elastic force of the material ; another portion is converted into heat, and this portion remains in the body after the elastic force has restored it to its original form, and can only be got rid of by convection.

Thus there are two causes operating in heating a gun exclusive of the very small effect due to the heated products of combustion. Let us now examine what would be the result of this heating upon the various constructions of guns.

Take first the homogeneous gun, of which the state of strain is represented by diagram A, page 12 . The strain at the inner surface of the gun during explosion is about 27 tons, whilst at the outer circumference it is only 3 tons per square inch. Now when the internal pressure is removed, the energy stored up in this strained mass is converted into heat, and we may suppose the amount of heating to be directly as the amount of energy so converted and inversely as the quantity of material heated. This being so, it follows that the inner layer of the gun would be heated nine times as much as the extreme outer layer by reason of conversion of energy, but the mass heated in each layer being in proportion to its length, and the lengths being as $4 \frac{1}{2}$ to $19 \frac{1}{2}$, or as 1 to 4.3 nearly, the rise of temperature would be as $433 \times 9$ to I, i.e. thirty-nire times greater in the innermost than in the outermost layer, and it is easy to see how this inequality of temperature must cause great internal strain by expansion, and thus weaken the gun.

Let us now consider the case of the 9-inch gun, the strains of which are shown by diagrams $B_{1}$ and $B_{2}$. As regards the steel tube, the result of the explosion is to change the inner surface from a state of compression of II tons to a state of tension of 12 tors per square inch, and the outer layer from about 7 tons compression to about $2 \frac{1}{2}$ tons tension. Whilst this is going on the tube is giving out work in aid of the powder guns until it arrives at the neutral state, after which it is absorbing work; the whole tube is therefore cooling. Now let us take the outer hoop. The effect of the explosion here is to increase the initial tension of 6 tons to 17 tons at the inner, and from 2 tons to $4 \frac{1}{2}$ tons at the outer surface. Now when the internal pressure is removed the energy given out is expended, first in the compression of the tube, and this part of the energy gives rise to no change of temperature, but the whole of the rest of the energy represented by II tons at the inner and $2 \frac{1}{2}$ tons at the outer surface is converted into heat, and taking into consideration the masses the relative rise of temperature will be as $\frac{I I}{7 \frac{1}{2}}$ is to $\frac{2 \frac{1}{2}}{19 \frac{1}{2}}$, or as $I I \frac{1}{2}$ to I nearly. Thus it appears that whilst from this cause the tube is cooled, the hoop is heated and expanded, which is equivalent to reducing the initial shrinkage of the hoop.
But we have still to deal with the heat set up by the percussive force of the explosion. This we may assume to be some direct function of the induced strain. It will therefore, as regards the tube, be a maximum at the inner and will be zero at the outer surface, whilst it will be greater at the inner surface of the hoop as compared with the outer in the proportion of $I I$ to $2 \frac{1}{2}$ (assuming it to vary directly with strain).

Lastly, as regards the heat imparted from the powder gases. It may be shown that in the very short time of the operation this is confined to a very thin layer of the inner surface of the tube. The final result then is, that the inner surface of the tube is heated, whilst the outer surface is probably actually cooled, at the same time the inner surface of the hoop is considerably heated, and the outer surface also heated, though to a much less degree. The effect of the changes must therefore be to weaken the gun, though in a very different manner from the case of the homogeneous gun.

We come now to the wire gun, diagram E. Here the work done by the powder gases is represented by the arm $B$ HOMNB, less the area $B C N$, that is, by the area CHOMNC. When the internal pressure is removed, the whole of this is converted into heat, but a portion of this between $\mathrm{C}$ and $\mathrm{N}$ would be neutralised by the cooling effect of the wires whilst converted into mechanical energy in passing from the compressive to the neutral state, and consequently the heating of the gun, though not absolutely uniform throughout, would be very nearly so. The heating from the percussive action would also be nearly uniform, being rather greater towards the inner surface. Now it can be shown that if a gun properly constructed either with hoops or wire be uniformly heated, the strains are not affected, and it therefore follows that in the wire gun the effect of heating is very slightly to alter the conditions and strength of the gun, and the wire gun, therefore, is in this respect far superior to the hooped systems.

We have now pointed out the difference in the mode of construction with hoop and with wire, we have compare 1 the two systems and shown that for strength, facility, and economy of construction, the wire system has greatly the advantage; we have refuted the objections which have been taken to it, and the task which we undertook is completed. Doubtless it will occur to our readers to ask how it is that a system which promises so fair, and which was brought prominently forward upwards of a quarter of a century ago, has never till quite recently been tried by the gun-makers. How is it that millions upon millions have been spent at Woolwich on hoop guns and that this system has been persistently neglected?

We know that not only was it brought before the Ordnance Select Committee, twenty-seven years ago, and that not as a mere idea, but accompanied with experimental facts, which, as the late Mr. Bidder, then (I860) President of the Institute of Civil Engineers, stated publicly, established such a primấ facie case as should have received the attention of Government, but we know further that at various times since it has been fruitlessly urged that trials of the system should be made.

We presume that those who had the decision of such matters were so satisfied with what they were doing, and had so much confidence in their own system that they never gave their serious attention to what they thought to be the dream of a theorist. The inexorable logic of facts seems, however, at last to have come into play, and we believe that the recently-constituted Crdnance Committee is at present seriously engaged in the reconsideration of the whole subject of gun construction, and that wire guns will be admitted to be within the region of practical gunmaking.

We trust it may be so, and that the system may be fairly tried, but in order that the trial may be fair, it is essential that it be conducted with due regard to those principles which it has been our object to explain-that 
the initial tensions of the wire coils be duly calculated and applied We insist specially on this, because not only has the Woolwich practice hitherto been to treat the shrinkage question in a hap-hasard rule of thumb method, but also Sir William Armstrong, in his late address as President of the Institution of Civil Engineers, made light of the precise degree of initial tension, and spoke of the tendency of the explosive force to effect an adjustment of the strains.

We cannot too strongly protest against such a view, as crude and unscientific, and any results which may be obtained from guns so constructed must be inconclusive as regards the principle of wire construction.

In concluding this article we bring before our readers sketches of three types of wire guns showing the application of the principle. The first is a heavy muzzle-loading gun, designed by the writer for land defences (Figs. $I$ and 2). The gun is furnished with rollers on the trunnions at $\mathrm{G}$, and recoils up a curved inclined plane, I I I, which is mounted on a turnable, so as to be capable of training in any direction in azimuth. The elevation is given by a hydraulic lift at $\mathrm{K}$. The construction of the gun is shown in Fig. 1 , in section. $\mathrm{AA}$ is the inner tube; $\mathrm{BB}$ the wire coiled on it; $\mathrm{C}$ the breech plug; $\mathrm{EE}$ is a heavy casting of cast iron, against which the breech plug rests, and which also forms the trunnions, $\mathrm{G} \mathrm{G} ; \mathrm{K} \mathrm{K}$ is a cast-iron casing covering the chase of the gun, and attached to the casting $\mathrm{E} \mathrm{E}$ by strong iron bolts, $\mathrm{F} \mathrm{F}$. In this gun there is no longitudinal strain on the chase; the recoil being taken up by the insertion of the heavy mass behind the breech plug and by the force of gravity on the ascending planes of the carriage, aided by compressors.

The second type, Fig. 3, is a muzzle-loading gun mounted on an ordinary carriage. The main trunnions are behind the breech and are connected to the carriage trunnions $B$ by side links $C$, so that the longitudinal strain is transmitted direct from the breech to the carriage without the intervention of the chase of the gun.

Figs. 4 and 5 represent the type for heavy breech-loading guns. In this case the breech plug is fixed in a massive block, A A, which slides backwards and forwards along the side rods, B B. Through this block passes an eccentric shaft, $c$, which terminates on each side in the side rods $\mathrm{B} \mathrm{B}$. When the eccentric is in its forward position the sliding block closes the breech. In the backward position the breech is open and the gun tops up on the forward trunnions $\mathrm{E}$, so as to allow of the introduction of the charge as shown in Fig. 5. When the charge is introduced the preponderance is restored to the breech end, the gun falls back to its normal position, the eccentric is removed, the breech closed, and the gun is ready for firing.

In all these cases it is obvious that there is no longitudinal strain on the chase of the gun, and it is obvious that so far as construction is concerned there is no limit to the possible size of the gun.

\section{JAMES A. LONGRIDGE}

\section{BEN NEVIS OBSERVATORY}

$\mathrm{T}$ $\mathrm{HE}$ conditions of weather on Ben Nevis are now such as to render it impracticable and hazardous to continue the daily observations satisfactorily. I have therefore judged it best to discontinue them, after a very successful season, under the auspices of the Scottish Meteorological Society, of five months from June I, without the break of a single day. The work at the six intermediate fixed stations has, I am very pleased to say, been well and generally punctually kept up throughout, and I trust that much good will result. Simultaneous observations were of course made at the observatory at Achintore, Fort William. The Stevenson's screens at these stations have now been made firm by wire stays to withstand the storms of winter. Yesterday
Colin Cameron, the guide, accompanied me. The track was snowed up, and it was necessary to force a way through great banks and drifts of snow. The average depth was two feet; once we got off our course in the blankness of thick cloud-fog and trackless snow. To-day the weather was very bad on the summit, the hut was partly filled by drift, and the south-east gale was so violent at times that I could hardly make way. Possibly I shall attempt weekly or periodical ascents during the winter to keep up the registrations of the rain-gauges and self-recording thermometers.

I have to-day commenced provisionally a three-hourly system of observation at Fort William (including 3 a.m.). The special features are sea temperature, ozone, and the reading and setting of the self-registering instruments on each occasion. Of course all the other usual elements are three-hourly observed also. Further particulars are reserved for a future number. CLEMENT R. WRAGGE

Fort William, November I

\section{THE OYSTER INDUSTRY OF THE UNITED STATES}

A VERY complete account of the history and present A condition of the oyster industry of the United States has been recently prepared by Ernest Ingersoll, under the direction of Prof. Baird, United States Commissioner of Fisheries. The importance of this industry it is not easy to over-estimate, and the United States Government deserve every credit for their efforts to preserve and extend it.

As having an important bearing on the question, the oyster-beds of the maritime provinces of Canada are briefly referred to. The eastern coast of the province of New Brunswick is washed by the Gulf of St. Lawrence ; down in the bottom of the Gulf lies the long, irregularly shaped Prince Edward's Island, between which and the mainland flow the shallow but troublesome currents of Northumberland Strait. The shores on either side of this Strait are for the most part low bluffs of reddish soil and sloping meadows; there is little solid rock, few prominent beadlands, but a continuous line of shore, shelving very gradually into water, nowhere deep; many rivers come down along the coast of the Gulf, and at the mouth of each there is an estuary proportionate to the size of the stream, from the mighty channel of the St. Lawrence to the miniature bay of Bedeque. Most of these estuaries are shallow, and most of them are protected from gales. This condition of affairs seems well suited for oyster growth, since nearly all of these estuaries either contain or contained large colonies of these mollusks. Except at its western end, Prince Edward Island is engirdled with oysters. That most beautiful salt-water lake in the world, the Bras d'Or, which occupies the whole interior of Cape Breton Island, fattens multitudes of oysters. These Canadian oysters are of large size, and have thick, strong shells; oysters with shells trom eight to ten inches in length are not extraordinary. The best are not the longest, but those with straight and narrow, or evenly-rounded shells. All the oysters on the eastern shores of North America, belong to the species known as Ostrea virginiana, which embraces many varieties, of which $O$. borealis is perhaps the best marked. Except at wholly unsuitable places, it is to be found almost without interruption from the northern shores of the Gulf of Mexico and the coast of Florida to the Canadian districts just referred to. It is, however, said not to be found along the eastern shores of Maine, nor in the Bay of Fundy, though the shells, in a semi-fossil state, are dug up in quantities from the deep mud in the harbour of Portland, Maine.

Mr. Ingersoll gives a very interesting account of the former extent and condition of the native beds in the Gulf of Maine, and of the evidence of the immense con- 